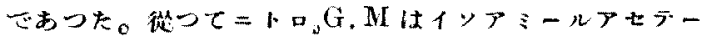

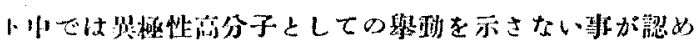
bto

\section{[III]洘察}

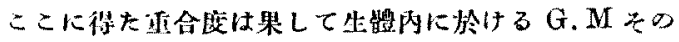

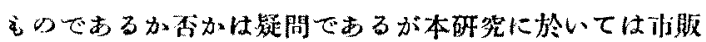

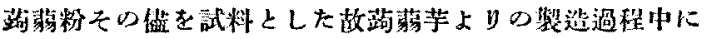

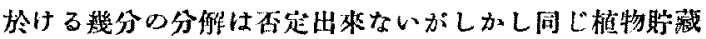

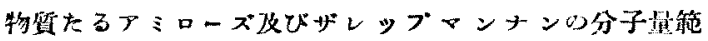

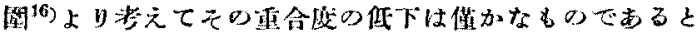

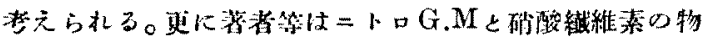

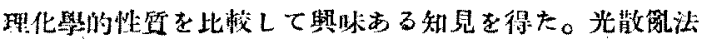

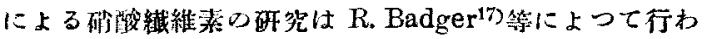

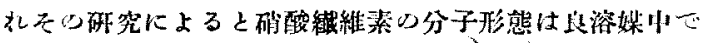

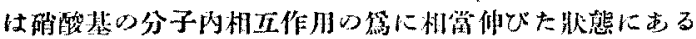

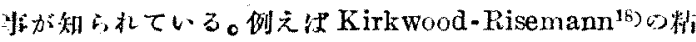
睃理論に率づく effective bond lengthは䄪 $45 \AA$ 位にな

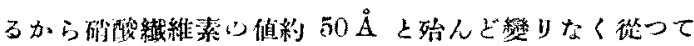

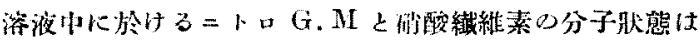

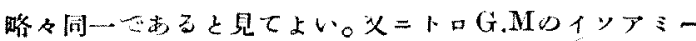

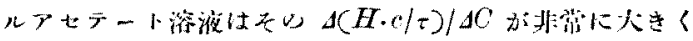

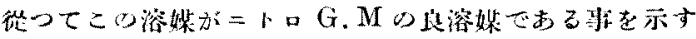
上共に粘废に於ける Huggins の $k^{\prime}$ 定紧电 0.64 ここの

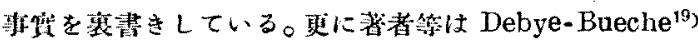

16) A. L. Potter, W. Z. Hassid, J. Am. Chem. Soc. 70, 3774 (1948).

17) R. Badger, R. Blaker, J. Phys. \& Colloid Chem. 53, 1050 (1949).

18) J. Kirkwood, J. Risemann, J. Chem. Phys. 16, 565 (1948).

$10)$, Debye, 1. Bueche, J. Chem. Phys, 16, 573 (1948),
い糊庭式に伐つて shielding function $\phi(a)$ 计定して みた。印市 $[\eta]=\left(\Omega_{*} / M\right) \phi(\sigma)$ に於いて $[\eta]=800(\mathrm{cc} / \mathrm{g})$ として $\sqrt{\left\langle R^{2}\right\rangle}=1380 \AA$ とすれば $\phi(\sigma)=0.22$ であ る。これから分子罢に對する指数を求めると $\alpha=0.95$ と

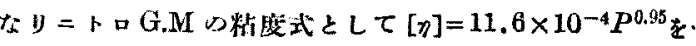
與え5 。

$[\eta]=K P a$ に於いてKの倠としては确酸陚維素中= トロザレップマシナンについて與えられている倠と大䯙

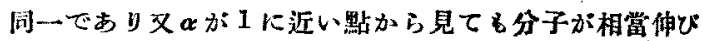
た狀㮩にある事が推察される。

\section{[IV]總括}

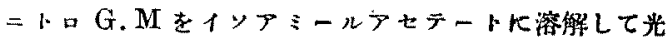
散剑度法に化つて分子量 271,000(重合度は的 1000) 奴

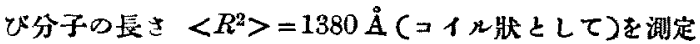
すると共に effective bond length=的 $45 \AA$ なる势を知 り更に溶液䉼度を湘定して $[\eta]=K P^{\infty}$ に於いて $K=$ $11.6 \times 10^{-4}, \alpha=0.95$ 見出し極性基の影䨂を阻止出來 る狀意では㗂酸瀻維素と略々同样な舉動を示す事を明ら かにした。

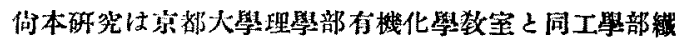
維化學数空と口其同研究に依つて行われたるのであり野

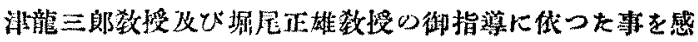
謝すると共に本研究透行に當り衔援助下された高橋光洋 氏並びに㟫心分啡器の使朋について御侹宜を計られた當

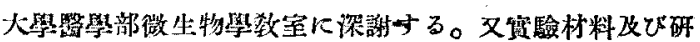

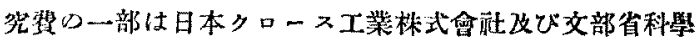

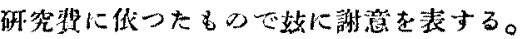

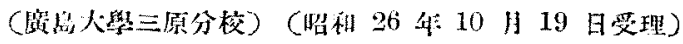

\title{
微 量の水銀の定量法について
}

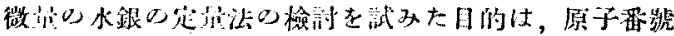
が水银が 80 番，金が 79 番，舛りムが 81 番心ある

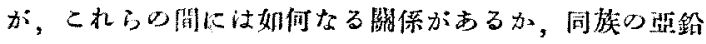

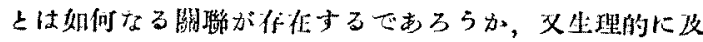
汇す彭悡といら點なする。

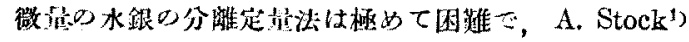

1) A. Stock, Z. angew, Chem. 44, 200 (1931).

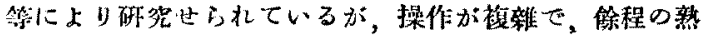

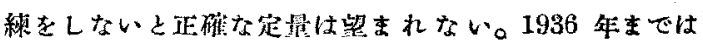
N. Straford ${ }^{2}$ に上り色々连へられているが，その後水銀

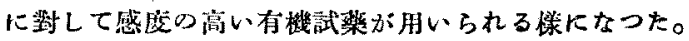
此色法としては、硫化水銀法，ジフェニルカルバジト 法, ジフェニルカルバン゙ン法, ロ一が=ン法, ジキゾン

2) N. Straford, Analyst 61, 608 (1996). 


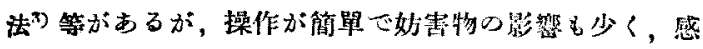

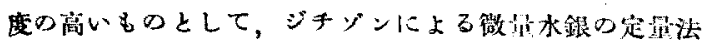
について檢部を行つた。

\section{實、驗 の 部}

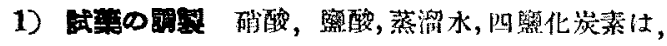

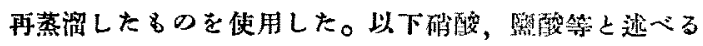
が何れる再蒸溜を行つたものでする。アンモニア水は，

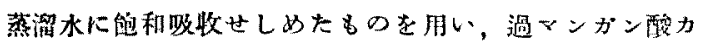
リは市販特級品を蒸溜水加ら再結晶をしたものを $5 \%$ 溶 液とした。祭酸七ドロキシルアミ゙ン溶液は蒸溜水に溶獬 し，5\% 溶液となしたるのを，像めジチザン四鼠化荻素 楁液と振つて水銀を除去したものを优肪した。過酸化水

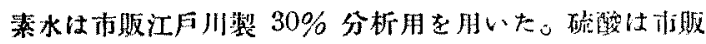

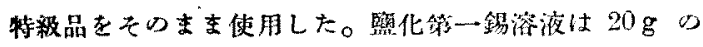

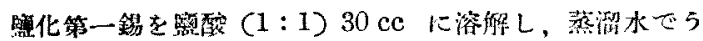
すわて $100 \mathrm{cc}$ とし，不溶分は湿士し、ジチジン溶液て

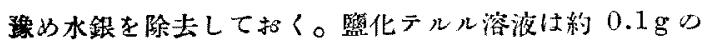

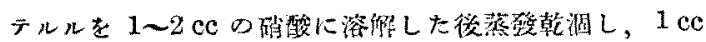

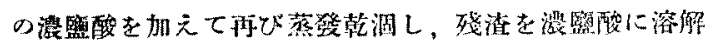

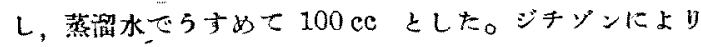
水銀を踭め除去して握く。 $1 \mathrm{cc}=1.2 \mathrm{mg}$ のテルル合 む溶液を使用した。

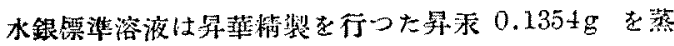

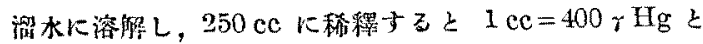

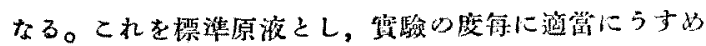
たのを使用する。

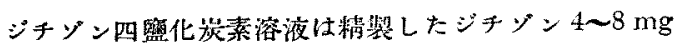

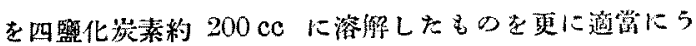
すかて优用した。

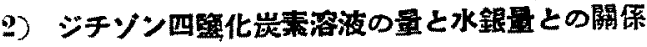

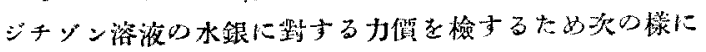
行つた。即ち小型分液溜斗に水銀溶液をとり, 全能を

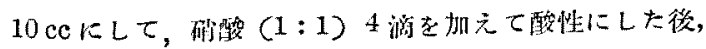

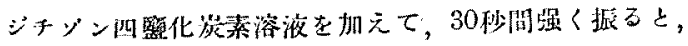
水銀が存在す扎ばジチン゙ン溶液は水銀を反盟して登齿色 を呈する。そこて整く放置すると水溶液い膡とジチジン 溶液々の層に分猚するから，酒栓を開いてジヂン溶液 を除去し，手びジチン゙ン溶液を加えて同栐に操作し，水 銀による橙带色が坐じなくなるす心繰返し，加えたジチ

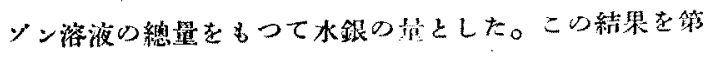

3) H. Fischer, G. Leopold, $Z$. anal. Chem. 103, $2 \pm 1$ (1935); H. Wichmann, J. Assoc. Offic. Agr. Chemists. 23, 292 (1940); Friedo M. Kuze, J. Assoc. Offic. Agr. Chemists 31, $438(1948)$.

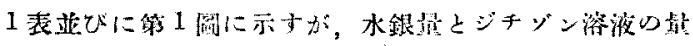
とは直線的に比例し，この方法にょつて水银の等量が可

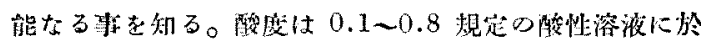
いて最是好維果老昰た。

解 1 表 水鈸とジチゾンと口關伱

\begin{tabular}{|c|c|c|c|}
\hline No. & $\begin{array}{c}\text { 水銀の足 } \\
\gamma\end{array}$ & 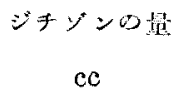 & 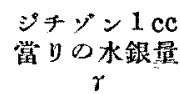 \\
\hline 1 & 4.0 & 0.360 & 11.1 \\
\hline 3 & 8.0 & 0.730 & 11.0 \\
\hline 3 & $1 \overline{2} .0$ & 1.110 & 10.8 \\
\hline 4 & 20.0 & 1.740 & 11.5 \\
\hline 5 & 30.0 & 2.530 & 11.9 \\
\hline 6 & 40.0 & 3.430 & 11.7 \\
\hline 7 & & 本均 & 11.3 \\
\hline
\end{tabular}

我 1 阔

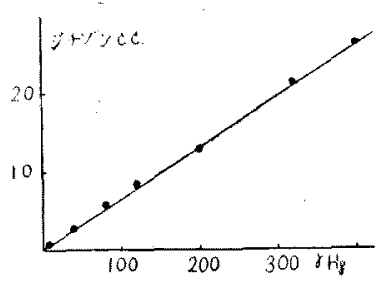

3）銀の共存に於ける水銀の分嚾 銀が其伊する時は

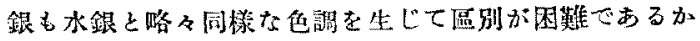

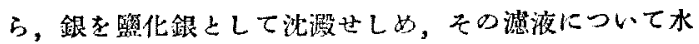
銀の定昷を行つたが，銀 200 r 4 $\mathrm{mg}$ の其存に於いて $8 \sim 40 \gamma$ の水銀を $2 \gamma$ 以下の新差で定照出来た。

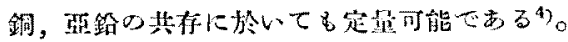

4) 抽出法による水銀の分離定量法 野荣㤝の水銀の

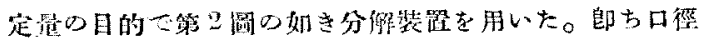

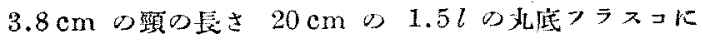

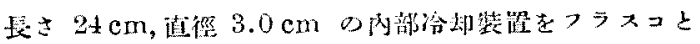

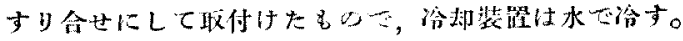

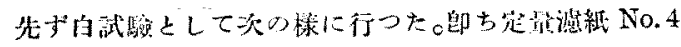

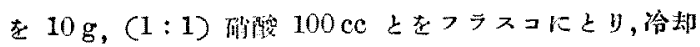

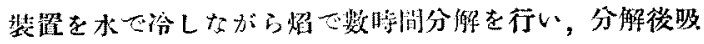

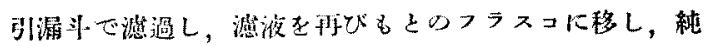
邀マンがン酸力y $10 \mathrm{~g}$ 老加えて俆丸に加熱し，完企に 有機物を分解する。泾訨後 $30 \%$ 過酸化水素水 $10 \mathrm{cc}$ を 加えて完全にマンがン党然透明な液にした後，約30分 者沸し，再び汾却して $500 \mathrm{cc}$ の分液漏斗に溶液を移し，

4) H. Flscher, G. Leopoldi, Z, anal.Chem. 103, 241 (1935), 
2 间

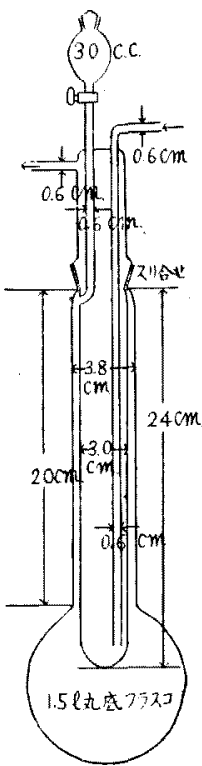

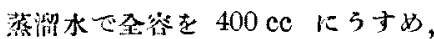

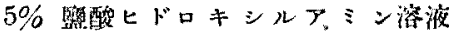
$10 \mathrm{cc}$ 加无, 過利のジチン゙ン四留

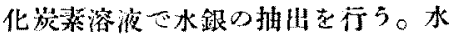
銀を抽出したジチ・゙ン溶液は他心分 液漏斗儿分踓し，硫酸(1: 1$)^{4}$ 滴， 蒸溜水 $10 \mathrm{cc}$ 及代 $5 \%$ 過マンガン 酸力り溶派 $5 \mathrm{cc}$ 老加えて上〈振留 ナるとジチジンは分解して水跟は水 溶液に移るから，ジチサン溶渡の展 在除去した㷋，5\%"ヒドロキシルア ミン溶液 5 cc を加えて西びジヂ ン溶液て水銀の淛是老行つた。そ0 絬果は 1 打, $12.0 \gamma \mathrm{Hg} ， 2$ 间, 11.3r $\mathrm{Hg}$ となり，平均 $11.6 \gamma \mathrm{Hg}$ の

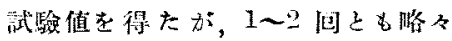
一致した值を示し，而办なり大き い值心する。

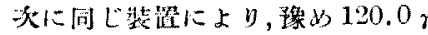

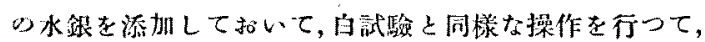

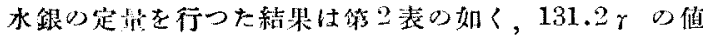
を得た。白試驗值を差引くと $119.6 r$ とすり，添加した 水銀は完全に四收される舟老認内た。

\section{第 2 表}

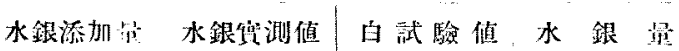

\begin{tabular}{l|l|l|l}
$120.0 \gamma$ & $131.2 \gamma$ & $11.6 \gamma$ & $119.6 \gamma$
\end{tabular}

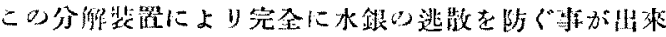
30

次に A. Stock $\left.{ }^{5}\right)^{6}$ に上机代，試桬中にも滤維にもかな

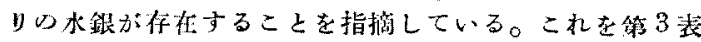
籍 3 表 試染中心水銀 $r / 100 \mathrm{cc}$

\begin{tabular}{|c|c|c|c|c|c|}
\hline 試 & & 䉾 & A. Stock & 染 & 诸 \\
\hline 鼠 & 酸 & 粗装品 & $50-220$ & & 82 \\
\hline$"$ & & 分析用 & 0.03 & & - \\
\hline 硫 & 酸 & 粗器品 & 180 & & - \\
\hline$"$ & & 分析用 & $3.0^{\circ}$ & & 2 \\
\hline 酳 & 酸 & & 65 & & 5 \\
\hline 蟻 & 酸 & & - & & 1 以下 \\
\hline 砧 & 酸 & 分析用 & 0.1 & & 1 以下 \\
\hline
\end{tabular}

b) A. Stock, Natumissenshaften 17, 498 (1941).

6) A. Stock, Z, angew. Chem. 44, 200 (1981).
に示す。メ W. O. Winkler ${ }^{7}$ \&過マンガン酸カリ，過

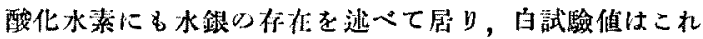

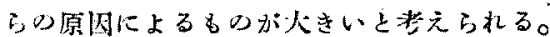

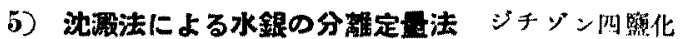
炭素による水銀の抽出法は識等が多胡に存在すると完全

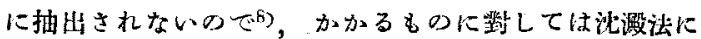

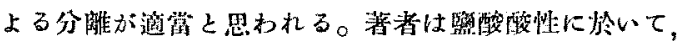

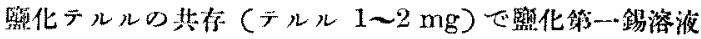

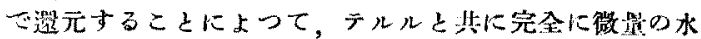
銀を沈溉せしめることを㥸めた。この方法り利然は，テ

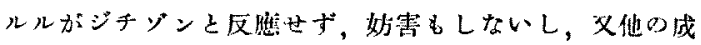
分上の分埕が完全に行われ，試樂の種類も少くてすみ，

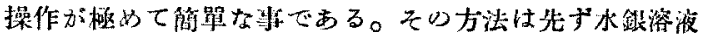

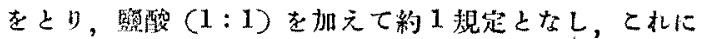

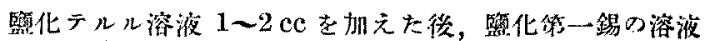

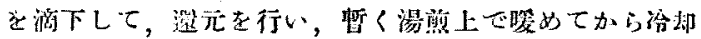

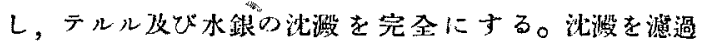

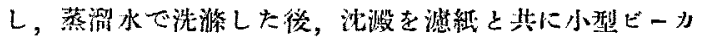

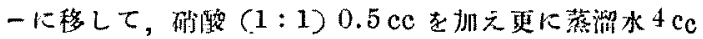
を加えておだやかに渡りて溶解し，一分に冷却した後， 滤液を小型分液漏斗に移して全客を $10 \mathrm{cc} と し, \mathrm{pH}$ を 1 に媩節してジチジンで湉定を行つた。その絬果を第4 第4表 テルルとの甚沈による水銀の分倠定监

\begin{tabular}{|c|c|c|c|c|c|}
\hline No. & $\frac{\text { 水銀合量 }}{r}$ & $\begin{array}{c}\text { 促䀧值 } \\
\gamma\end{array}$ & 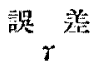 & 倩 & 考 \\
\hline I & 4.0 & 4.0 & 0 & & . \\
\hline 2 & 12.0 & 12.3 & +0.3 & & \\
\hline 3 & 20.0 & 19.4 & -0.6 & & \\
\hline 4 & 40.0 & 40.2 & +0.2 & & \\
\hline 5 & .80 .0 & 80.5 & +0.5 & & \\
\hline 6 & 120.0 & 121.9 & +1.9 & & : \\
\hline 7 & 8.0 & 8.0 & 0 & 約 $3 \mathrm{~g}$ & $\mathrm{NaNO}_{3}$ 添加 \\
\hline 8 & 12.0 & 11.8 & -0.2 & 約 $5 \mathrm{~g}$ & $\mathrm{NaNO}_{3}$ 添加 \\
\hline
\end{tabular}

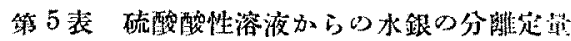

\begin{tabular}{|c|c|c|c|c|c|}
\hline No. & 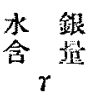 & $\begin{array}{c}\text { 水銀溶液 } \\
0 \text { 符 } \\
\text { ce }\end{array}$ & $\begin{array}{l}\text { 硫酸口 } \\
\text { 規定底 } \\
\frac{\mathrm{N}}{\mathrm{N}}\end{array}$ & $\begin{array}{c}\text { 离测僬 } \\
r\end{array}$ & $\begin{array}{c}\gamma \\
\gamma\end{array}$ \\
\hline 1 & 8.0 & 2.0 & 1 & 7.9 & -0.1 \\
\hline 2 & 8.0 & 2.0 & 3 & 6.3 & -1.7 \\
\hline 3 & 20.0 & 5.0 & 1 & 19.8 & -0.2 \\
\hline 4 & 40.0 & 10.0 & 1 & 38.7 & -1.3 \\
\hline
\end{tabular}

7) W. O. Winkler, J, Assoc. Offic Agr, Chemists, 19, 233 (1986). 8) K. Kuroda, Bull. Chem. Soc. Japan 15, 439 (1940). 


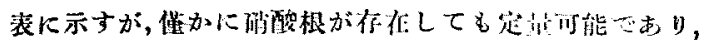

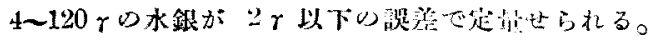

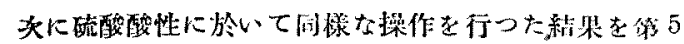

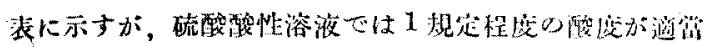

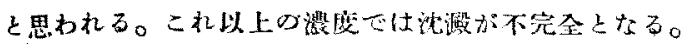

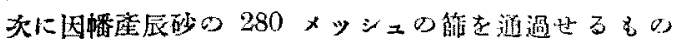
$0.5 \mathrm{~g}$ ⿸ pH 5.8 の沵溜水 $200 \mathrm{cc}$ に加えて $25^{\circ} \mathrm{C}$ の恒

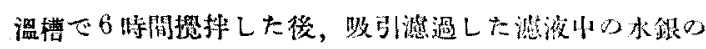

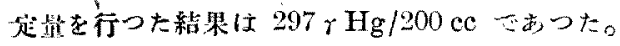

總括

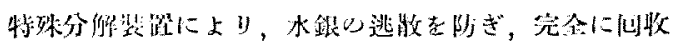

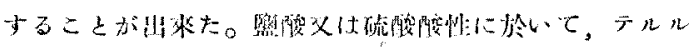

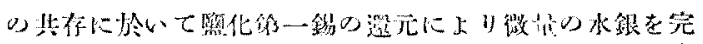

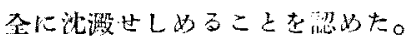

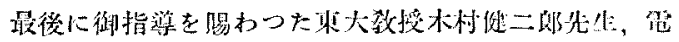

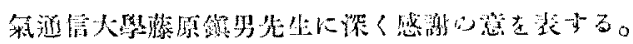

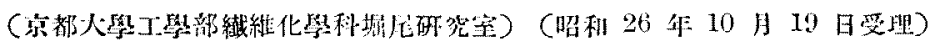

\section{Lamm のスケール法による高分子の擴散測定（第 2 報） 纖維素キサントゲン酸ソーダの擴散測定}

西鸟安则・稻坦提

\section{1. 緒論}

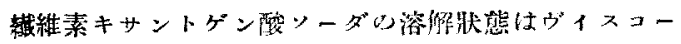

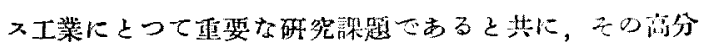

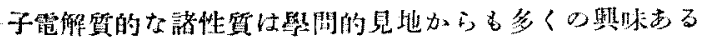

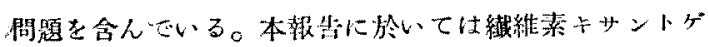

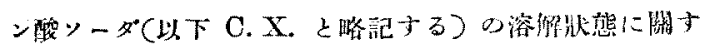

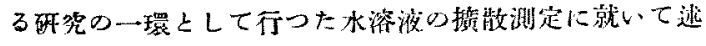
ヘる。

\section{2. 實 驗}

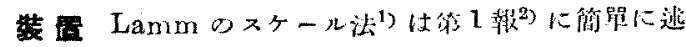

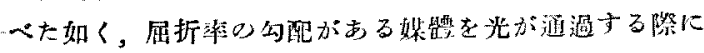

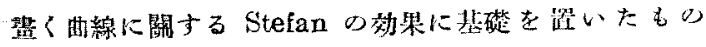

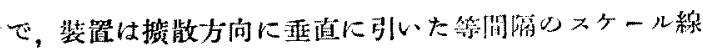

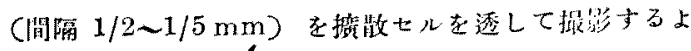

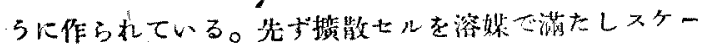

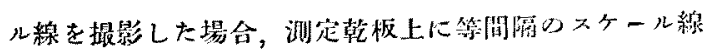

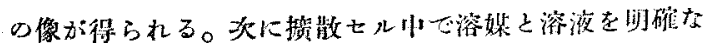

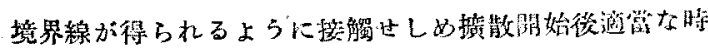

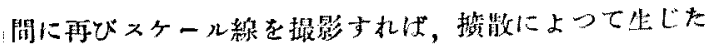

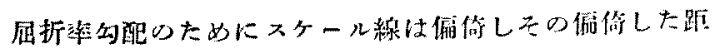
睢を $Z$ とすれ代

$$
Z=G \cdot a \cdot b \cdot \mathrm{d} n / \mathrm{d} x
$$

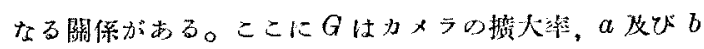

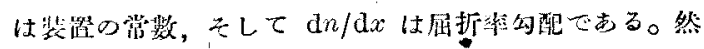

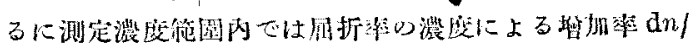
$\mathrm{d} c$ は一定と見做し得る故 $\mathrm{d} n / \mathrm{d} x$ は $\mathrm{d} c / \mathrm{d} x$ に比例する。 從つて备スタール線の俩佮をミクロコンパレーターた测

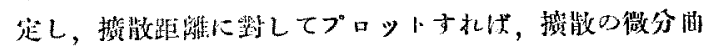
線分得ら机る。

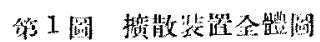

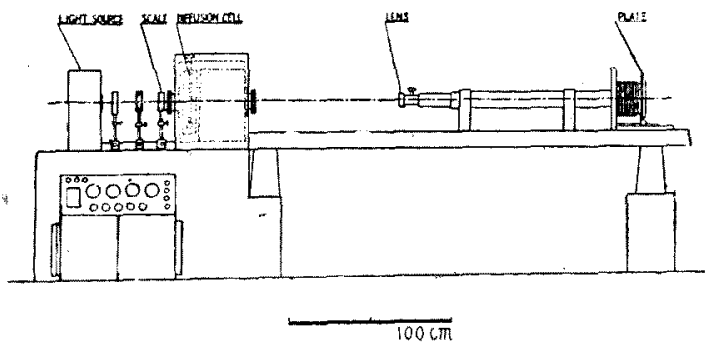

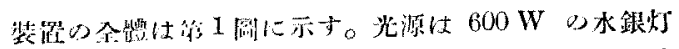

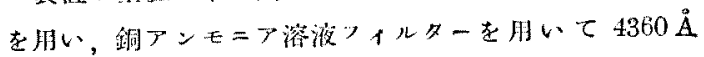

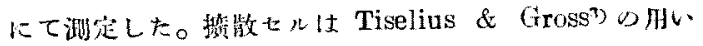

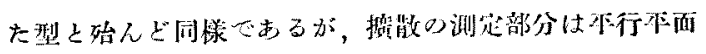

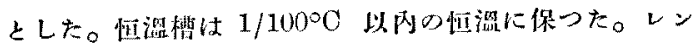

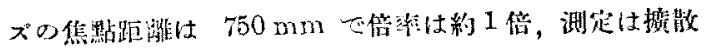

3) A. Tiselius, D. Gross, Kolloid-Z. 66, 11 (1984).

1) O. Lamm, Z. physic. Chem. A 138, 318 (1928).

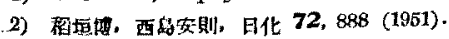

